Military Technical College Kobry El-Kobbah, Cairo, Egypt

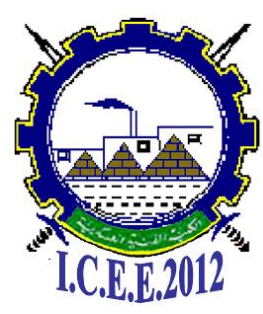

$6^{\text {th }}$ International Conference on

Chemical \& Environmental Engineering 29 -31 May, 2012.

\title{
ENMC-2
}

\section{SENSITIVITY AND DETONATION PARAMETERS OF 4, 6-DIAZIDO- $N$-NITRO-1, 3, 5-TRIAZIN-2-AMINE}

\author{
Tomáš Musil*, Robert Matyáš*, Ondřej Němec*, Martin Künze*
}

\begin{abstract}
Highly dense nitrogen-rich compounds are potential high performance energetic materials for use in industrial scene or military. 4,6-Diazido-N-nitro-1,3,5-triazin-2amine (DANT) is relatively a new substance on which characterization and detonation parameters were tested. The sensitivity of DANT to impact, friction and electric discharge was also determined. Sensitivity to impact is between PETN and RDX, sensitivity to friction is higher as PETN. DANT's relative strength is $108 \%$ of TNT. We also calculated and measured detonation parameters such as pressure and detonation velocity. Theoretical detonation parameters are $8205 \mathrm{~m} \cdot \mathrm{s}^{-1}$ and $30.3 \mathrm{GPa}$. Temperature of autoignition is $156^{\circ} \mathrm{C}$.
\end{abstract}

Keywords:

4,6-Diazido-N-nitro-1,3,5-triazin-2-amine; DANT, detonation parameters, sensitivity

Institute of Energetic Materials, Faculty of Chemical Technology, University of Pardubice, Studentska 95, 53210 Pardubice, Czech Republic. st13233@ student.upce.cz 


\section{Introduction}

4,6-Diazido- $N$-nitro-1,3,5-triazin-2-amine (DANT, see scheme 1) - this relatively simple molecule was first reported only four years ago by Fronabarger et al. [1]. The more extensive study of this molecule focused on its synthesis, analysis, structure and its sensitivity to mechanical stimuli was published recently by us [2]. Cesium and rubidium salt of DANT were suggested as green primary explosives [1]; salts of DANT with nitrogen bases (e. g. aminoguanidium, 4-amino-1,2,4-triazolium, guanizinium) were patented as a high performance energetic salts for military and industrial use [3]. Not all explosive properties of DANT (primarily performance or detonation velocity) have been published yet. Therefore the present study is focused on explosive parameters and sensitivity of DANT.<smiles>Nc1nc(N)nc([N+](=O)[O-])n1</smiles>

\section{Scheme 1 DANT molecule}

\section{Experimental}

\subsection{Synthesis of DANT}

DANT was prepared by a three step synthesis (see scheme 2). The 2-amino-4,6-dichloro1,3,5-triazine (first intermediate) was prepared by adding the cyanuric chloride into aqueous ammonia according to published procedure [4]. The second intermediate is formed by reaction of aqueous sodium azide with 2-amino-4,6-dichloro-1,3,5-triazine in an ethanol suspension [5]. Nitration is the last step of the synthesis. 2,4-Diazido- $N$-nitro-1,3,5-triazin-2amine was nitrated by a cooled nitric acid according to Fronabarger and Williams procedure [1] to yield DANT. The product was recrystallized from methanol (product does not melt). The whole three step synthesis including the analysis of intermediates is described in detail in our pervious paper [2].

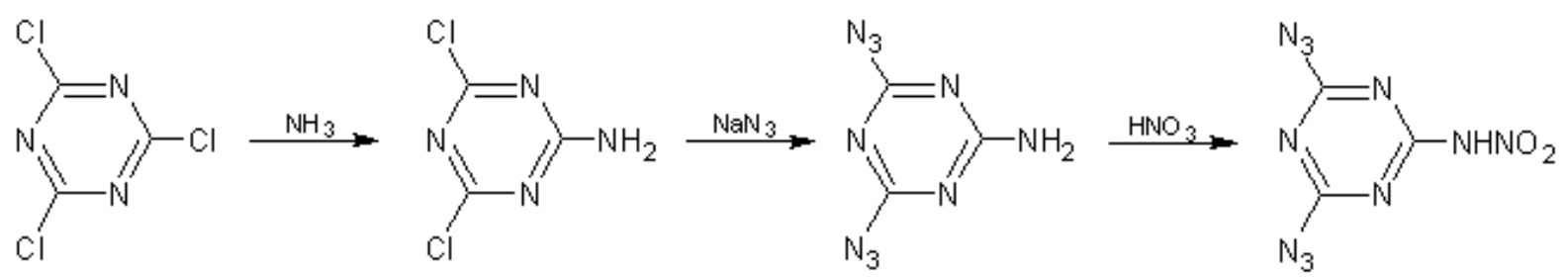

Scheme 2 Synthesis of DANT

\subsection{Characterization of other used explosives}

Pentrit and hexogen (see Scheme 3) were used for comparison with DANT sensitivity. Pentrit with trade name "Pentrit NS" (with particles lower than $200 \mu \mathrm{m}$ ) and was provided by Explosia a. s. company; hexogen was provided by Chemko Strazke company. 
<smiles>O=[N+]([O-])N1CN([N+](=O)[O-])CN([N+](=O)[O-])C1</smiles>

RDX<smiles>Nc1nc(N)nc(N)n1</smiles>

TTA<smiles>O=[N+]([O-])CC(CO[N+](=O)[O-])(CO[N+](=O)[O-])CO[N+](=O)[O-]</smiles>

PETN

Scheme 3 Examples of common explosives.

\subsection{Temperature of autoignition}

The autoignition point was measured with the DTA 551-Ex by OZM Research. The $25 \mathrm{mg}$ samples were measured in test tubes, which were in a special furnace filled with Wood's metal. The heating rate was $5^{\circ} \mathrm{C} \mathrm{min}^{-1}$. Each sample was tested at three independent measurements.

\subsection{Hygroscopicity evaluation}

Samples of DANT were dried over phosphorus pentoxide for 1 day. Then the samples were weighed (to within $0.1 \mathrm{mg}$ ) and quickly placed to a desiccator containing $18.6 \%$ sulphuric acid (relative humidity of $90 \%$ is thus obtained). During the following 7 days, the samples were weighted.

\subsection{Sensitivity to impact}

The fall hammer apparatus (produced by Reichel and Partner) was applied for determination of impact sensitivity with a $0.5 \mathrm{~kg}$ heavy hammer for lead azide, a $1 \mathrm{~kg}$ hammer for PETN and DANT, and a $2 \mathrm{~kg}$ hammer for RDX. Both; piston and cylinders; were produced by OZM Research.

\subsection{Sensitivity to friction}

The sensitivity to friction was determined using BAM type friction apparatus FSKM-08 for DANT, PETN and RDX samples; lead azide was measured on small BAM friction apparatus FSKM-PEx. Porcelain plates type no. BFST-Pn-200 and porcelain plates type BFST-Pt-100S were used. The apparatus, porcelain plates and pegs were produced by OZM Research. The probit analysis was used for determination and calculation of sensitivity of all samples.

\subsection{Relative strength}

The relative explosive strength was measured by a ballistic mortar. Values are reported as a relative performance of TNT. For each measurement, $5 \mathrm{~g}$ DANT was wrapped in a polyethylene foil and inserted into the mortar enclosed by a steel projectile and then fired using a non-electric detonator (No. 8, provided by Sellier \& Bellot Company). Three tests were carried out.

\section{Results and discussion}

\subsection{Temperature of autoignition}

The temperature of autoignition of DANT is $156^{\circ} \mathrm{C}$. This value corresponds with value $149^{\circ} \mathrm{C}$ determined at DTA in our previous study (heating rate $5^{\circ} \mathrm{C} \cdot \mathrm{min}^{-1}$, sample weight $10 \mathrm{mg}$ ) [2] . Fronabarger et al. published onset at $175^{\circ} \mathrm{C}$ and $179^{\circ} \mathrm{C}$ for peak on DSC measurement. 
However the heating rate was higher $\left(20^{\circ} \mathrm{C} \cdot \mathrm{min}^{-1}\right)$ [1]. In comparison; autoignition temperature of $\mathrm{RDX}$ is $204^{\circ} \mathrm{C}$ and for PETN is $192^{\circ} \mathrm{C}$ [6].

\subsection{Hygroscopicity}

The hygroscopicity of DANT was measured at $30^{\circ} \mathrm{C}$ during 7 days (at 24 hour period). After exposing the sample for a time period it was removed from desiccator and the weight gain was recorded. It was determined that DANT is non-hygroscopic, gaining $0.02 \%$ surface moisture.

\subsection{Sensitivity of DANT to impact}

Dependence of probability of ignition on impact energy is presented on Figure 1. Sensitivity of DANT to impact is between PETN and RDX. Values of PETN and RDX are lower than commonly reported. This phenomenon can be caused by distinct apparatus, sets (pistons and cylinders) or methodology used for measuring in various laboratories.

\subsection{Sensitivity to friction}

Sensitivity of DANT to friction was determined on BAM friction apparatus and compared with other common explosives (PETN and RDX). Sensitivity of DANT to friction is high; it exceeds PETN (see Figure 2).

\subsection{Relative strength}

Despite the high content of nitrogen molecules of DANT its relative strength is $108 \%$ TNT. It is slightly less than PETN (119\% TNT) and RDX (122\% TNT).

\subsection{Detonation parameters}

Detonation velocity $D\left(\mathrm{~m}_{\mathrm{s}} \mathrm{s}^{-1}\right)$ and detonation pressure $P(\mathrm{GPa})$ of DANT was calculated using Kamlet and Jacobs equations [7]. Results are summarized in Table 1. The density and heat of formation were taken from literature.

Table 1 Detonation parameters

\begin{tabular}{|c|c|c|c|c|c|c|}
\hline & $\begin{array}{c}\mathrm{M}_{\mathrm{r}} \\
\left(\mathrm{g} \cdot \mathrm{mol}^{-1}\right)\end{array}$ & $\begin{array}{c}\rho^{[\mathrm{A}]} \\
\left(\mathrm{g} \cdot \mathrm{cm}^{-3}\right)\end{array}$ & $\begin{array}{c}\Delta H_{\mathrm{f}}^{[\mathrm{B}]} \\
\left(\mathrm{kJ} \cdot \mathrm{mol}^{-1}\right)\end{array}$ & $\begin{array}{l}D_{\max }[\mathrm{C}] \\
\left(\mathrm{m} \cdot \mathrm{s}^{-1}\right)\end{array}$ & $\begin{array}{c}P_{\max }{ }^{[\mathrm{D}]} \\
(\mathrm{GPa})\end{array}$ & $\begin{array}{c}\mathrm{OB}^{[\mathrm{E}]} \\
(\text { wt. } \%)\end{array}$ \\
\hline DANT & 223.1 & $1.849^{\lfloor 2\rfloor}$ & $723.7^{[2]}$ & 8205 & 30.3 & -32.37 \\
\hline PETN & 316.1 & $1.760^{[8]}$ & $-538.9^{[8]}$ & 8652 & 32.8 & -10.12 \\
\hline RDX & 222.1 & $1.820^{[8]}$ & $67.1^{[8]}$ & 8862 & 35.1 & -21.61 \\
\hline TTA & 204.1 & $1.720^{[9]}$ & $1053^{[10]}$ & 7639 & 25.2 & -47.03 \\
\hline
\end{tabular}

Detonation parameters of DANT are slightly lower than for PETN. However it exceeds cyanuric triazide.

\section{Conclusion}

The sensitivities and explosive properties of 4,6-diazido- $N$-nitro-1,3,5-triazin-2-amine were reported. Final survey of the main explosive properties of DANT in comparison with those for RDX and PETN is summarized bellow: 


\begin{tabular}{lccc}
\hline & DANT & RDX & PETN \\
\hline Temperature of autoignition $\left({ }^{\circ} \mathrm{C}\right)$ & 156 & 204 & 192 \\
Impact energy for 50\% probability of initiation $(\mathrm{J})$ & 1.68 & 3.59 & 1.33 \\
F of I for 50\% probability of initiation & 37 & 80 & 30 \\
Friction force for 50\% probability of initiation $(\mathrm{N})$ & 40.7 & 75.5 & 127 \\
Calculated detonation velocity $\left(\mathrm{m} . \mathrm{s}^{-1}\right)$ & 8205 & 8862 & 8652 \\
Calculated detonation pressure $(\mathrm{GPa})$ & 30.3 & 35.1 & 32.8 \\
Relative explosive strength $(\%$ TNT) & 108 & 122 & 119 \\
\hline
\end{tabular}

\section{References}

[1] J. Fronabarger, M. E. Sitzmann, M. D. Williams, Method for azidotriazole, nitrosoguanazine, and related compounds, US patent 7375221 B1, 2008.

[2] T. Musil, R. Matyáš, : 4,6-Diazido- $N$-nitro-1,3,5-triazin-2-amine (DANT) - synthesis and characterization, Propellants, Explos., Pyrotech., in print.

[3] Y. Huang, Y. Zhang, J. M. Shreeve, Nitrogen-rich salts based on energetic nitroaminodiazido[1,3,5]triazine and guanazine, Chem. Eur. J., 2011, 17, 1538-46

[4] J. T. Thurston, J. R. Dudley, D. W. Kaiser, I. Hechenbleikner, F. C. Schaefer, D. HolmHansen, Cyanuric chloride derivates. I. Aminochloro-s-triazines, J. Am. Chem. Soc., 1951, 73, 2981-2983.

[5] Yu. A. Azev, O. L. Guselnikova, N. A. Klyuev, C. V. Shorshnev, V. L. Rusinov, O. N. Chupakhin, Produkty prevrashchenii azidoproizvodnykh $s$-triazina s nekotorymi $O$ - i $N$ nukleofilami, Zh. Org. Khim. Russian, 1995, 31, 1566-1572.

[6]. D. Klasovitý, S. Zeman, A. Růžička, M. Jungová, M. Roháč, cis-1,3,4,6tetranitrooctahydroimidazo-[4,5-d]imidazole (BCHMX), its properties and initiation reactivity, J. Hazard. Mater., 2009, 164, 954-961.

[7] M. J. Kamlet, S .J .Jacobs, J. Chem. Phys., 1968, 48, 23-25.

[8] R. Meyer, J. Köhler and A. Homburg Explosives, $6^{\text {th }}$ edit., VCH publishers, Weinheim, Germany 2007.

[9] T. C. Sutton, Structure of cyanuric triazide $\mathrm{C}_{3} \mathrm{~N}_{3}\left(\mathrm{~N}_{3}\right)_{3}$, Philos. Mag., 1933, 15, 10011018 .

[10] E. G. Gillian, Synthesis of nitrogen-rich carbon nitride networks from an energetic molecular azide precursor, Chem. Mater., 2000, 12, 3906-3912. 


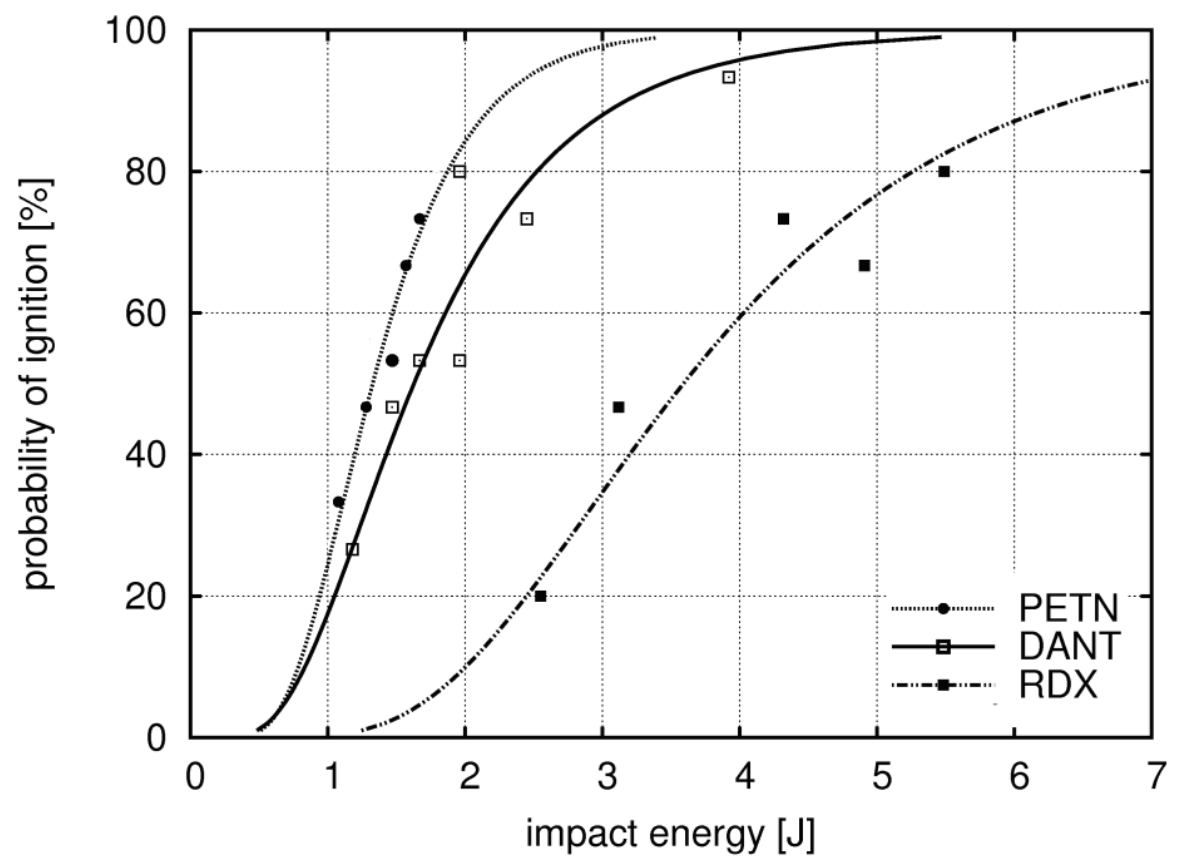

Figure 1 A comparison of impact sensitivity of DANT, PETN and RDX.

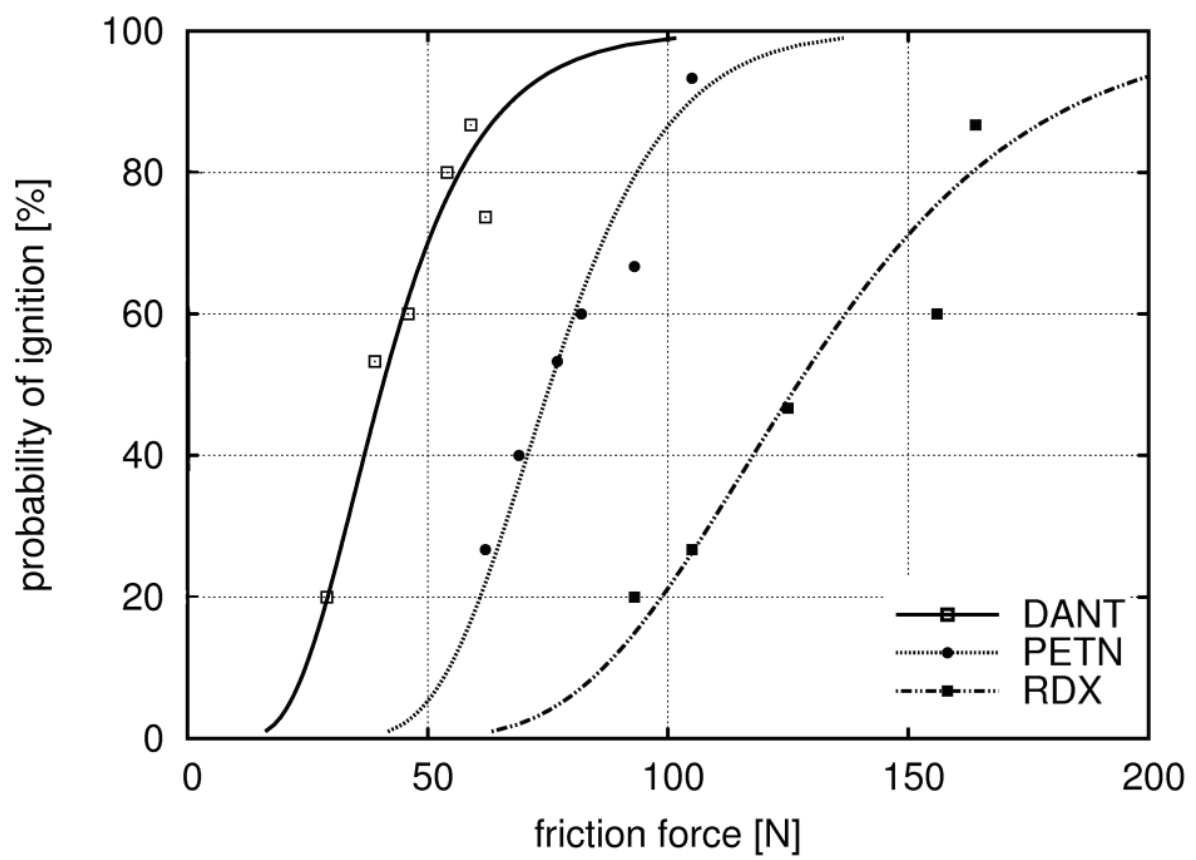

Figure 2 A comparison of friction sensitivity of DANT, PETN and RDX. 